\title{
O EMARANHADO DE FIOS QUE ENVOLVE OS CONTEXTOS DE INFLUÊNCIA E DE PRODUÇÃO DA BNCC
}

\author{
Adriana Corrêa $a^{1}$ \\ José Carlos Morgado ${ }^{2}$
}

\section{INTRODUÇÃO}

Em nenhum momento da história do Brasil se viu uma iniciativa com tamanha magnitude, nem que tenha mobilizado tantos atores - sobretudo gestores e professores de diferentes níveis de ensino - e a sociedade civil, como o processo de construção da Base Nacional Comum Curricular (BNCC). Daí a pertinência do projeto de investigação que vimos desenvolvendo, através do qual procurámos captar a forma como o processo foi elaborado, destacando o seu carácter político, sem nos preocuparmos demasiado com a sequência dos factos, pois, como destaca Frigoto (2011, p. 237), “(...) não é o tempo cronológico que define uma conjuntura, mas a natureza dos acontecimentos e dos fatos e as forças sociais que os produzem".

Para o efeito, nesse estudo procurámos, a partir das narrativas dos atores, direta ou indiretamente envolvidos na elaboração da BNCC, captar os significados e as suas perceções sobre o documento e o seu processo de elaboração. Acresce o facto de as análises documentais, os conteúdos de portais e até as páginas da web que consultámos terem servido para identificar vozes presentes, a epistemologia empregada na arquitetura do documento, os deslizes e até algumas (in)verdades utilizadas.

Sem dúvida que o processo de recolha de dados exigiu, da nossa parte, o refinamento do material e uma análise aturada, sobretudo porque envolveu atores de destaque no cenário nacional brasileiro, com carreiras acadêmicas consolidadas, com cargos estratégicos em órgãos do Estado e lideranças no poder legislativo, empresários e empresas, o que nos obrigou a ter alguns cuidados na condução das entrevistas e no tratamento dos dados. Por vezes, foram citadas pessoas, entidades, disputas e acordos específicos, o que consignou características específicas ao enredo quer político, quer da produção do texto - que envolveu a BNCC.

No nosso caso, o interesse circunscreve-se aos contextos de influência e da produção de texto e está relacionado com a arquitetura do documento e a epistemologia utilizada, bem como com os paradigmas e o discurso oculto que sinalizou toda a sua elaboração. Assim, a tentativa de

\footnotetext{
${ }^{1}$ Doutoranda do Curso de Ciências da Educação, especialidade de Desenvolvimento Curricular, da Universidade do Minho.

2 Professor Associado no Departamento de Estudos Curriculares e Tecnologia Educativa da Universidade do Minho. Investigador integrado no CIEd (Centro de investigação em Educação).
} 
compreender o enredo e as suas linhas de construção, permitiu-nos desocultar a sua génese, as disputas de grupos e as associações que, dado o seu posicionamento, tiveram grande influência na definição dos pressupostos e das conceções incorporadas no texto.

Assim, com base no ciclo de políticas proposto por Ball $(1994)^{3}$, procurámos compreender os motivos, as formas de mobilização e a arquitetura curricular assumida pelos atores que estiveram envolvidos na sua produção. Para o efeito, caracterizamos o período do estudo, de 2015 a 2018, que abarcou o início da construção, a homologação e o processo de implantação do documento na Educação Infantil e no Ensino Fundamental.

Nessa caracterização abordamos a génese da BNCC, uma vez que algumas narrativas recolhidas nessa fase do estudo apresentam dados controversos, tornando visíveis disputas por protagonismo e pela legitimidade do documento, por parte dos atores envolvidos na sua produção.

\section{O PRIMEIRO NÓ DA TRAMA: A GÉNESE DA BNCC}

O emaranhado de fios que perpassam os contextos de influência política e da produção de texto corporiza um conjunto de interesses e enquadra-se num determinado paradigma, que interferiram na configuração da BNCC, gerando disputas de poder, de epistemologias, de ideologias em discussões extremamente ácidas, segundo os entrevistados durante a nossa pesquisa. Assim se compreende que a digressão que efetuámos tenha sido necessária para, de alguma forma, dar sentido ao que estava a ser discutido e proposto.

Como política de Estado, consubstanciada pelo ordenamento jurídico que foi amplamente discutido e utilizado como justificação para a sua elaboração, a construção da BNCC serviu também como alegação para trazer à tona os indicadores da educação básica, sobejamente conhecidos, e que estimularam o reconhecimento da sua necessidade. Acresce o facto de toda legislação educacional do país ter nas suas bases jurídicas a defesa de dispositivos que explicitam, de algum modo, o direito de todos à educação. Um direito que deve ser comum, mas que nem sempre é fácil de concretizar. Por isso, torna-se oportuno colocar a seguinte questão: A que direitos tais documentos se referem?

Para compreender de forma mais profunda todo esse processo, procurámos, através das narrativas dos atores ${ }^{4}$, direta ou indiretamente, envolvidos na elaboração da BNCC, captar os

\footnotetext{
${ }^{3}$ Utilizamos apenas os dois primeiros contextos no estudo - o contexto de influência e o da produção do texto - da construção da BNCC, por causa de ter sido aprovada somente em 2017 (Educação Infantil e Ensino Fundamental) e do prazo de implantação estabelecido pelo CNE.

${ }^{4} \mathrm{Na}$ nossa pesquisa realizámos entrevistas com três grupos de indivíduos que participaram na elaboração da BNCC nas suas diferentes versões (V1, V2, V3). Grupo de Especialistas (GE), coordenadores, assessores e redatores do documento; Grupo de Agentes Públicos (GAP) técnicos e dirigentes do MEC que participaram nesse processo entre 2014 a 2017, e Conselheiros do CNE com mandatos até 2017, representantes da UNDIME e CONSED e o Grupo do Movimento pela Base Nacional Comum Curricular (GMBNC).
} 
significados, os sentidos e as suas perceções sobre o documento e o processo de elaboração. Além disso, as análises documentais que realizámos ao longo do estudo, os conteúdos de portais e as páginas da web consultadas serviram para identificar as vozes presentes, a epistemologia utilizada na arquitetura do documento, os deslizes e as verdades empregadas.

Não podemos esquecer que o documento em apreço se inscreve no domínio curricular e que o currículo é um território de disputas, um terreno movediço, onde as forças coercitivas e as lutas do campo ideológico e epistemológico se movem e procuram legitimidade. Daí o dinamismo que caracterizou o nosso estudo. É que, desvelar as vozes que deram contornos e operaram com a sua autoridade constituída, através das narrativas dos sujeitos que participaram e das instituições que impuseram as suas crenças, não foi um processo tranquilo, muito menos consensual. No entanto, a natureza do documento estudado e o contexto político em que o mesmo foi produzido animaram-nos e estimularam-nos a percorrer alguns caminhos sinuosos e cheios de armadilhas.

Além do mais, a agenda proposta para o Século XXI tem contornos que precisam de ser evidenciados, quando um país, como o Brasil, define como necessidade a construção de um currículo nacional. Nota-se que o discurso da necessidade foi disseminado por grupos privados (MBNC), para além da urgência imposta pelo Plano Nacional de Educação (PNE), o que permitiu que protagonizassem a construção da BNCC. Ainda, a agenda das redes de políticas transnacionais foi colocada na arena de disputas, não só no Brasil, mas em muitos outros países, como demonstram os estudos de Dale $(2004,2008)$ e de Ball (2016) e que Thiesen (2016, p. 95) destaca da seguinte forma:

\begin{abstract}
Este modelo de governança gerencialista que integra a gestão pública nos interesses privados, que classifica a educação como um serviço, que se orienta pelo principio da eficiência com base em resultados, que estimula a competição e os ranqueamentos, que avalia por padrões externos, que descentraliza responsabilidades e controla recursos, constitui, portanto, significante que sustenta e mantém a hegemonia da pauta educacional colocada pela agenda política global na rota da educação, tanto na esfera transnacional quanto brasileira.
\end{abstract}

Perante a necessidade de conhecer a génese da BNCC, foi preciso compreender, principalmente junto dos Agentes Públicos, a forma como foram conduzidas as discussões. Segundo as declarações de um entrevistado (GAP 4), que trabalhou no MEC antes da construção da V1, existiu uma "versão silenciada" da Base, desconhecida por muitos, que foi organizada por uma equipe de especialistas de diferentes Universidades, em 2014, coordenada pela Prof ${ }^{a}$. Jaqueline Moll. Esse documento, que foi recentemente lançado em forma de preprint, consiste num trabalho desenvolvido em torno dos "Direitos à aprendizagem e ao desenvolvimento na educação básica: subsídios ao currículo nacional" ${ }^{\circ}$. Como nos foi garantido, nunca existiu a pretensão de esse se assumir como um

\footnotetext{
${ }^{5} \mathrm{O}$ documento, pode ser acedido em:
} 
currículo nacional, embora envolvesse um conjunto de elementos que poderiam contribuir para a elaboração futura dos currículos dos Sistemas de Ensino.

No entanto, foi a partir desse documento que se delineou a organização da BNCC, sob a coordenação da Prof ${ }^{a}$. Maria Beatriz Luce, então Secretária da Educação Básica do MEC, tendo definido a base concetual e metodológica e o planeamento do processo de construção. Além disso, essas ações foram apresentadas num Seminário com a participação da $\mathrm{UNDIME}^{6}$, do $\mathrm{CONSED}^{7}$, do CNE e de associações profissionais, como descreve uma entrevistada (GAP 3):

Segunda ação, foi chamar as entidades relacionadas da educação reconhecidas, ANPED, ANPAE, Fórum de Educação, associações, e eles compareceram em massa, estabelecemos um cronograma de trabalho, e ele foi até 2015, mas com a saída da Prof ${ }^{a}$. Maria Dulce e a entrada do Prof. Manuel Palacios, que não assume esse documento e faz mudanças radicais, por isso se chama esse documento, como a primeira versão da Base.

Para além das ações do MEC, com a mudança da Prof ${ }^{a}$. Maria Beatriz Dulce, assume a mesma Secretaria o Prof. Manuel Palácios que não considera todo o planeamento anterior, gerando um certo constrangimento nos bastidores do MEC com a não continuidade dos trabalhos apresentados pela sua antecessora, principalmente como retrata a GAP 3, que não leva em conta o documento, por isso designado "versão silenciada" da Base, pelos motivos já destacados. Nota-se que o mesmo Governo possui as suas próprias descontinuidades nas políticas internas, com embates de toda a ordem, em que as concessões e as ideologias passam a ser moeda de troca. Com a mudança da equipe do MEC, outros encaminhamentos foram dados. Esta pesquisa não os alcançou, mas, certamente, as contingências do período e os paradigmas utilizados carregam igualmente alguns significados.

No entanto, para os elementos do grupo do MBNC, foram eles que de alguma forma iniciaram o processo de construção, fato esse corroborado pelo entrevistado GAP 3, que afirma que participou numa reunião convocada pelo movimento onde se discutiu a agenda nacional. Todavia, como representante do MEC, teve o cuidado de deixar claro que essa era uma responsabilidade do Estado.

Coincidentemente, nessa época, o MBNC nos chamou para uma reunião em São Paulo. Foi a primeira reunião em que participamos. A professora (cita o nome) e eu fomos representando o MEC e eles começaram a apresentar a mobilização deles para a Base. Mas, para nossa surpresa, não apontavam nada desse movimento que começa em 2009, pensando já na Base. Então, naquela reunião, consideramos que a construção da Base era uma responsabilidade do Estado; face a isso, a gente retomou o que estava sendo construído, e que o MEC estava em processo de construção, porque eles estavam pesquisando os currículos internacionais e a defesa do MBNC era de que fosse alguma coisa capaz de avaliar. O que o MBNC defendia era que a Base tivesse a especificação de conteúdos. (GAP 3)

\footnotetext{
https://acervodigital.ufpr.br/bitstream/handle/1884/55911/direitos_a_aprendizagem_e_ao_desenvolvimento_na_e ducacao_basica_subsidios_ao_curriculo_nacional-preprint.pdf?sequence=1\&isAllowed=y

${ }^{6}$ União Nacional dos Dirigentes Municipais de Educação.

${ }^{7}$ Conselho Nacional dos Secretários de Educação.
}

Revista Teias v. $20 \bullet$ n. 59 out/dez $2019 \bullet$ Outras epistemologias e metodologias nas investigações sobre currículo 238 
Para Apple (1999, p. 35) “deve existir um determinado grupo de 'intelectuais' que aplicam e conferem legitimidade às categorias, fazendo com que as formas ideológicas pareçam neutras". A pseudoneutralidade no interesse pelo currículo nacional foi a tónica dos discursos dos representantes do MBNC, tanto nas entrevistas para a pesquisa, como no espaço ocupado na mídia. O relato do entrevistado $n^{\circ} 6$, do GMBNC, confirma a tese de que foi preciso convencer os atores da necessidade de construção e "mobilizá-los".

\begin{abstract}
A primeira coisa do movimento, o objetivo era de colocar o tema como prioridade na agenda do Brasil, e aí, ao longo de 2013 e 2014, isso aconteceu com muita articulação com o CONSED, UNDIME, MEC e CNE, garantindo que muitos desses atores, fossem os atores que lideraram a construção e implementação da Base e que fossem sensibilizados para a importância desse documento no Brasil. Basicamente, esse foi o papel do Movimento, sensibilizar esses atores, e a gente fez por meio de muitos estudos, pesquisas, muitos diálogos, a gente trouxe muita gente, para fazer essas conversas, gente de fora do Brasil, e eu acho que foi super bem sucedida essa primeira etapa de sensibilização, porque o MEC, o CONSED e UNDIME rapidamente ao longo desses anos, se convenceram muito e se tornaram grandes embaixadores dessa discussão.
\end{abstract}

O grupo do MBNC reivindica para si a iniciativa de, primeiramente, ter mobilizado e alertado os Agentes Públicos para a necessidade de construção da BNCC, apelando sempre para o ordenamento jurídico, mais especificamente ao Plano Nacional de Educação ${ }^{8}$. Por vezes, num tom de preocupação ou de arrogância, foi-nos revelado que a tentativa de construção já tinha sido desencadeada no pós LDB, quando estudavam a forma de o fazer, o que nos permite intuir que terá sido a construção dos Parâmetros Curriculares Nacionais (PCNs), mas que não terá tido carácter normativo.

GMBNC 5 e GE V3: Já o MBNC, foi criado pelo apelo da necessidade do Brasil ter um currículo. Quando foi promulgada a LDB, a partir dos anos 90, nós estudamos muito a Lei e, achávamos que tinha que ter diretrizes. Eu fui autora das diretrizes (PCNS) do Ensino Médio do Governo de FHC, a história mostrou que os PCNs não eram suficientes, e aí atentando para o que estava acontecendo em outros países, principalmente nos EUA, é muito parecido connosco. Houve uma construção social, daí o que se chegou na Base, começamos a discutir no MBNC.

É preciso compreender os procedimentos que envolveram a produção dos PCNs na década de 1990, durante a gestão do Presidente Fernando Henrique Cardoso, uma vez que a equipe responsável pelo documento foi, em grande parte, a mesma que concluiu a versão homologada da BNCC, sobretudo no que diz respeito ao Comitê Gestor, que seguiu a mesma lógica e a arquitetura curricular. O ponto sensível dessa discussão é o de que os entrevistados ligados ao MBNC e que participaram da elaboração dos PCNs, seja porque estavam no MEC ou porque foram os seus atores, como também

${ }^{8}$ O PNE define como prazo até 2024.

Revista Teias v. 20 • n. 59 • out/dez 2019 • Outras epistemologias e metodologias nas investigações sobre currículo 239 
os redatores da $\mathrm{V} 3$, trouxeram sempre como referência o documento. $\mathrm{O}$ que nos permite pensar que a V3 foi a tentativa de ressuscitar os PCNs, mas agora com o apoio do CNE, que na altura não aprovou o documento por causa de divergências políticas. Um facto ratificado pelo Agente Público nº8:

GAP 8: A nova equipa do MEC, na V3 ajudou a construir o conceito de competências e a aplicá-lo. Vem da época dos PCNs. Essa equipe acredita nessas coisas, vem da equipe de SP do Governo FHC, que sempre se sentiram inconformados de que nós tivéssemos abandonado, gradativamente, o conceito de competência, para nos ligarmos mais à ideia de direitos de aprendizagem. Com a subida desse pessoal ao poder, voltaram à defesa da sua própria tradição e fizeram muita questão, de alguma maneira, de atropelar os dispositivos da Lei para colocar a sua marca, independente da forma como chegaram ao poder e, de alguma maneira, exerceram sua vontade.

Nesse processo de construção, importa lembrar que a BNCC se iniciou antes de o MEC desencadear o seu empreendimento. Além disso, merece destaque o papel desempenhado pela Secretaria de Assuntos Estratégicos ${ }^{9}$ do Governo Dilma, em que o próprio Ministro mobiliza um grupo de professores para discutir a elaboração do documento. Em matéria publicada na Revista Exame, em 13/9/2015, a reportagem trata da saída do então Ministro (o titular dessa pasta era tratado como Ministro) e cita a decisão de construir a BNCC.

(...) os problemas se agravaram quando o peemedebista decidiu incluir no plano uma proposta de diretrizes curriculares para a Base Nacional Comum da Educação, que define o que se espera que alunos aprendam em cada etapa da educação básica. Para auxiliares da presidente, Mangabeira extrapolou as suas funções, ao atropelar uma discussão que já ocorria no âmbito do MEC. "Quem apresenta proposta de educação é o MEC. (https://exame.abril.com.br/brasil/planalto-paralisa-mote-do-2o-mandato/).

A decisão de construir a BNCC não foi bem recebida pelo MEC, criando um mal estar entre os próprios membros do Governo. Isso deixou claro como é que as relações de poder se constituem, como, de resto, sublinha Bernstein (1988, p. 25) ao afirmar que "a eloquência do poder está no silêncio que produz". Neste caso, constatamos a existência desse "silêncio" na organização dos encontros que o próprio Ministro articula e realiza com especialistas para tratar do assunto, que foram feitos às escondidas, uma vez que só após a sua saída é que tivemos conhecimento dos fatos. Poucos entrevistados sabiam da existência do desejo da referida Secretaria capitanear a construção da BNCC.

GE 9 (V1/2): Lembro que outra Secretaria já havia começado a discutir, eu fui convidado, acho que era a Secretaria do Mangabeira (Unger), lá nós ouvimos falar de outros currículos do exterior, da Austrália e do Chile. Era um grupo mais seleto e tinha uma proposta bem ambiciosa. Era muito mais para construir um currículo mesmo. (...)Eu lembro de alguns nomes, mas não tinha um coordenador. Mas o trabalho lá, foi esfarelando, a princípio tinha nomes de referência nacional. O Ministro Mangabeira, foi quem coordenou os primeiros

\footnotetext{
${ }^{9}$ A Secretaria de Assuntos Estratégicos, foi responsável pelo mote da segunda (2 ${ }^{a}$ ) campanha da Presidente Dilma, intitulado "Pátria Educadora". No meio de disputas entre o MEC e a referida Secretaria que acaba por se intrometer na pasta da educação, o Ministro perde o cargo.
}

Revista Teias v. 20 • n. 59 • out/dez 2019 • Outras epistemologias e metodologias nas investigações sobre currículo 240 
trabalhos. Teve a participação de uma Fundação da Austrália e ele mesmo atuava como intérprete.

GAP 1: (...)As críticas, na época do $2^{\circ}$ mandato da Presidenta Dilma, onde o Ministro era o Sid Gomes e o Secretário da Educação Básica era o Palacios, houve conflitos, pois a Secretaria de Assuntos Estratégicos (SAE), do Mangabeira Unger, queriam fazer o documento da BNCC, uma vez que a SAE(Secretaria de Assuntos Estratégicos) é que tinha ligações com a ACARA (Fundação Australiana). Foi uma queda de braço, mas o MEC é que tomou a frente.

O enredo evocado pelos entrevistados dá sinais das disputas que estavam em jogo e na ordem do dia, seja no próprio Governo e nas equipes do MEC que foram se alterando ao longo de todo o processo, seja em outras Secretarias que queriam esse protagonismo. Durante a construção da BNCC (até 2017) tivemos seis (6) Ministros e, consequentemente, alterações nas respetivas equipas do MEC, o que nos permite concluir que cada gestão procurou imprimir as suas vontades e os seus enredos nessa história.

\section{PUXANDO OUTROS FIOS: OS PROTAGONISTAS QUE EMPRESTARAM AS SUAS VOZES AO DOCUMENTO.}

A construção da BNCC envolveu mais de duzentas pessoas ${ }^{10}$, diretamente os coordenadores, assessores de áreas e redatores e, indiretamente, alguns milhares, relativos a associações e entidades de classe, grupos empresariais designados de "nova filantropia"11, professores, gestores, etc. Todos, de alguma forma, emprestaram as suas vozes, a sua epistemologia, as suas vontades e os seus interesses na elaboração do documento, com maior ou menor protagonismo.

Convém sublinhar que tivemos três versões do documento ${ }^{12}$, neste artigo identificadas como V1/2 (versão 1 e 2) e V3 (versão 3), aprovado pelo CNE e homologado pelo MEC em dezembro de 2017, contemplando apenas a Educação Infantil e o Ensino Fundamental. No caso da V1/2, e de acordo com os entrevistados, a maioria não se conhecia, pois eram de origens distintas, sejam de IES, professores da Educação Básica e Técnicos de Secretaria, representados pelas cinco regiões do país. Além disso, procurámos analisar o currículo de cada especialista envolvido, no Portal do Conselho

\footnotetext{
${ }^{10} \mathrm{Na}$ V1/V2 foram 116 especialistas representados pelas cinco regiões do país, de Universidades Públicas (IES) e Privadas, professores em exercício na Educação Básica, técnicos de secretarias, dezasseis (16) assessores de áreas de IES públicas e dois coordenadores. A V3 contou com vinte e quatro (24)redatores da região sudeste, de IES públicas e privadas e professores da Educação Básica, e um coordenador de uma Fundação Privada, dos quais encontramos nos créditos das três versões.

11 Para Avelar e Ball (2017, p. 1), a nova filantropia "trata as doações como investimentos, resulta como retornos e quer envolver-se em decisões sobre como o dinheiro é usado".

${ }^{12} \mathrm{~A}$ nossa pesquisa concluiu que tivemos cinco (5) versões do documento. Antes da V1, a "versão silenciada" pode ser definida como a primeira, depois a V2, a V3 e por último a homologada, que depois de dar entrada no CNE, em 2017, foi analisada e discutida, retornando de seguida ao MEC para ajustes. Algumas áreas e/ou componentes curriculares sofreram alterações em toda a sua extensão, como foi o caso da Língua Portuguesa e da Educação Infantil, relatados pelo Grupo de Agentes Públicos, ligados ao CNE e por redatores da V3.
}

Revista Teias v. $20 \bullet$ n. 59 • out/dez $2019 \bullet$ Outras epistemologias e metodologias nas investigações sobre currículo 241 
Nacional de Desenvolvimento Científico e Tecnológico (CNPq) e noutras páginas da web, afim de conhecer a sua trajetória acadêmica e profissional, para identificar o lugar de onde falavam. Verificámos que nem todos os especialistas possuem, ou possuíam, na altura da pesquisa (até maio de 2018), os seus currículos no principal portal do país que integra as bases de dados de grupos de pesquisa e de instituições. Por isso, foi necessária uma busca nas páginas web de Secretarias Estaduais de Educação, bem como nas Fundações Privadas em que alguns especialistas prestam serviço.

De acordo com as coordenações da BNCC, a V1/2 adotou os seguintes critérios para a escolha de especialistas e assessores, uma vez que os professores em exercício na Educação Básica e os Técnicos das Secretarias foram indicados pelo CONSED e UNDIME.

GE 18 (V1/2): (...) Primeiro que fossem professores que atuassem em cursos de licenciatura e sua entrada no ensino, que fossem representativos das diferentes regiões do Brasil, e o terceiro critério, que nem sempre foi possível atender, era que fossem professores que tivessem tido algum envolvimento nos debates de reformas curriculares nas redes estaduais e municipais, ou participação em outra política pública do MEC, como PNAIc, PIBID, etc.

Os entrevistados, de forma unânime, indicaram de que forma foi feito o convite para participarem no processo, afirmaram que se enquadravam nos critérios definidos, ou porque já tinham participado em reformas curriculares, por serem professores de licenciaturas, ou porque tinham tido de alguma forma participação em políticas do MEC, o que foi corroborado nas suas trajetórias acadêmicas.

GE 5 V1/2: Bom, eu já estava participando de um outro Grupo de Trabalho que era uma fase inicial, a primeira ideia de Base, no documento de Direitos de Aprendizagem, com o grupo da Jaqueline Moll, durante quase 2 anos. (...) Os professores universitários ligados à formação de professores e de colégios de aplicação. Inicialmente fui convidado porque já tinha participação em outras políticas do MEC, pessoas envolvidas com o PIBID também. A minha entrada, se deu na Base, em função do primeiro critério, representando a IES.

Como já havíamos adiantado, a V1/2 contou também com muitos professores da Educação Básica e Técnicos de Secretarias Estaduais indicados pelos CONSEDs ou UNDIME. Nesse grupo, que está distribuído pelas cinco (5) regiões do país,todos os entrevistados afirmaram que foram convidados pelas respectivas entidades:

GE 9 (V1/2): eu fui convidado pelo CONSED. Não houve um edital de escolha. O meu Estado mandou um representante de Matemática e Química. Acho que nós, professores, fomos um termômetro para não ficar muito no mundo acadêmico, para ver se o que estava sendo feito tinha a ver com o chão da escola. Ficamos muito à vontade na equipe. Sempre fomos ouvidos, nos sentimos com poder de decisão.

Já na V3, a indicação foi feita através de contatos da coordenação do documento ou de pessoas ligadas à Secretária Executiva do MEC, em muitos casos professores que já tinham participado na construção dos PCNs. Como afirmamos anteriormente, o grupo era mais enxuto e todos da região 
sudeste. Em resposta à nossa indagação acerca de um número tão reduzido, foi-nos revelado que não havia necessidade, uma vez que foram considerados as versões anteriores: "nós nos sentimos confortáveis com um grupo menor, uma vez que o trabalho intenso já havia sido feito na V1/2." (GE 19, V3). Destaca-se que o novo grupo não teve os seus nomes revelados até à homologação do documento, no caso do Ensino Fundamental e da Educação Infantil. Por vezes, alguns entrevistados deste grupo revelaram a forma de alinhamento do documento com as orientações internacionais e mesmo com os grupos privados.

GE 1 (V3): Fui convidada pela Diretora do INEP, Maria Ines Fini, trabalhamos juntas em outros momentos. A preocupação da coordenação dos trabalhos era que compreendêssemos o conceito de Base Curricular. Até no contato com alguns profissionais do exterior foram feitos alinhamentos com esse pessoal do exterior e da Fundação Lemann, para contribuir com esse entendimento conceitual.

Convém lembrar que após a entrada no CNE, que analisou o documento, a V3 ainda foi alvo de algumas sugestões das audiências públicas, tendo posteriormente devolvido o documento ao MEC para realizar os ajustes necessários. De acordo um entrevistado, a sua indicação tinha sido feita pela Fundação Vanzolini ${ }^{13}$, que foi contratada pelo MEC para refazer o documento. A partir daí, uma nova equipe gera uma nova versão (V4), em algumas áreas específicas. A Fundação referida não faz parte do MBNC, o que não impediu que celebrasse um Acordo Técnico com o MEC, conforme D.O.U n ${ }^{\circ}$ 57, (de 23 de março de 2017), para prestação de serviços especializados para a gestão integrada dos processos necessários à consolidação, disponibilização, divulgação e discussão da $3^{\circ}$ versão da Base Nacional Comum Curricular (BNCC), com vigência de 22/03/2017 a 22/03/2019. Esse acordo custou ao erário público a quantia de $\mathrm{R} \$ 18.923 .297,00$.

GE 7 (V3): Nesse momento, já existia um convênio de terceirização aqui em SP da redação, com uma Fundação sem fins lucrativos famosa em prestar serviços educacionais que era a fundação Vanzolini. Exato, todo mundo faz parte, e trabalha para essa Fundação. No meu caso, o convite veio da Fundação Vanzolini.

Quando perguntámos aos Especialistas da V1/2 se tinham participado nas três versões do documento, apenas três pessoas disseram que sim. Os restantes afirmam que não foram contactados, nem informados da decisão tomada pelo novo Governo Temer e a equipa do MEC: "Desconsideraram

\footnotetext{
13 "A Fundação Vanzolini é uma instituição privada, sem fins lucrativos, criada, mantida e gerida pelos professores do Departamento de Engenharia de Produção da Escola Politécnica da Universidade de São Paulo (USP). A instituição tem como objetivo principal desenvolver e disseminar conhecimentos científicos e tecnológicos essenciais à Engenharia de Produção, à Administração Industrial, à Gestão de Operações $e$ às demais atividades relacionadas que realiza com total caráter inovador" (https://vanzolini.org.br/institucional/quem-somos/). De acordo com o seu curriculum vitae, no Linkedin, a Coordenadora da V3 atua na mesma Fundação.
}

Revista Teias v. $20 \bullet$ n. 59 • out/dez $2019 \bullet$ Outras epistemologias e metodologias nas investigações sobre currículo 243 
todo o debate realizado, sua trajetória e o histórico de construção. Não estava no espírito do novo Governo dar continuidade ao debate." (GE 2 V1/2).

No entanto, acreditamos que a escolha dos especialistas se ficou a dever à sua produção na Universidade, aos anos de pesquisa e de estudo, envolvendo também professores que atuam em sala de aula e trouxeram o olhar dos seus pares e a sua experiência. Alguns entrevistados ligados ao MBNC, ou mesmo do grupo de Agentes Públicos procuraram, durante as suas narrativas, desmerecer ou desqualificar os especialistas que participaram na construção do documento.

GAP 4: Não seja ingênua. Para quem eles trabalhavam? O que estou dizendo é que quem fez a V1 e a V2 foi o pessoal de Juiz de Fora. Ainda me lembro, que circulava que quem fez o trabalho (em OFF, não posso confirmar) teria sido o MBNC, que deu 60 nomes para fazer o documento da V1 e V2, mas teria sido usado um número muito pequeno. Foram convocados consultores do grupo que dominou. Na V3, eu sei quem fez, porque participei. Não sou ingênuo e apenas posso dizer que foi um grupo de paulistas. Você sabe que paulistas acham que a gente é mais "burra”. Não seja ingênua.

Ainda sobre os especialistas, algumas narrativas dão conta da falta de compromisso das IES, em relação ao conhecimento, colocando em xeque o seu papel na produção de novo conhecimento. A inserção da Universidade nas licenciaturas, nas escolas e noutras instituições educativas tem de ser ancorada em projetos e necessita de financiamento. Nesse sentido, na história recente, temos exemplos de Programas que têm procurado proximidade, como, por exemplo, o Programa Institucional de Bolsas de Iniciação à Docência (PIBID) ${ }^{14}$

GAP 6 e GMBNC ${ }^{15}$ : A academia está muito longe da vida real, lá do Acre, do Amapá, da Bahia,e lá as crianças tem direito de aprender, e lá as Universidades não vão. Eu tenho sérias críticas às Universidades que não chegam à escola. A escola vira o zoológico da academia, vamos lá, pesquisamos, dizemos que eles não prestam, mas não fazemos nada para ajudar.

GMBNC 5 e GE V3 ${ }^{16}$ : Olha a Universidade não tem muito o que dizer, mas isso não é de agora. Quando eu escrevi os PCNs do Ensino Médio, eu sempre disse que era uma tarefa da Universidade. A Universidade perde o protagonismo não só para as ONGs, para os órgãos, é lamentável que esteja fora disso. O problema que se coloca é o seguinte: Você sabe que ela nunca discutiu os parâmetros curriculares dos anos 90? Poucas licenciaturas os deram aos seus alunos para ler, a formação no Brasil, é desvinculada da realidade, "dançando na maionese". Nem a universidade privada ocupa esse espaço. Você tem obviamente exemplos pontuais. Mas, a gente não consegue trabalhar na escala que o país precisa. Temos 2 milhões e meio de professores que precisamos de atingir.

GAP 4: Por uma questão de transparência, devo dizer que eu participei do MBNC, quando ele começou. Depois fui para o Governo e saí. A gente precisava de criar competências no Brasil, para escrever habilidades. Nós não queríamos mais expectativas de aprendizagem,

\footnotetext{
14 “O programa oferece bolsas de iniciação à docência aos alunos de cursos presenciais que se dediquem ao estágio nas escolas públicas e que, quando graduados, se comprometam com o exercício do magistério na rede pública. O objetivo é antecipar o vínculo entre os futuros mestres e as salas de aula da rede pública. Com essa iniciativa, o Pibid faz uma articulação entre a educação superior (por meio das licenciaturas), a escola e os sistemas estaduais e municipais. "Disponível em http://portal.mec.gov.br/pibid 15 O entrevistado no. 6 faz parte do Grupo de Agentes Públicos e do MBNC.

${ }^{16} \mathrm{O}$ entrevistado no. 5 faz parte do MBNC e atuou como redator da V3.
} 
porque a expectativa não dialoga muito com o direito, daí a gente precisava de um conhecimento técnico, que infelizmente as nossas Universidades não nos deram, e continuam a não dar.

Sobre as críticas à Universidade, há que fazer algumas ponderações, sobretudo no que tange à sua desvinculação com a escola pública e a sociedade como um todo. Observa-se que as críticas vêm justamente de Agentes Públicos com vinculação ao MBNC, justificando a sua necessidade de trazer insumos técnicos, uma vez que a Universidade não os consegue oferecer. No entanto, dadas as contingências existentes e as condições objetivas dos professores, constata-se que, na maior parte dos casos, não existe espaço, tempo e verbas públicas para que a sua atuação seja mais pontual e mais significativa. Apesar disso, é preciso não esquecer que,

No outro extremo do continuum, temos as atividades de produção de conhecimento exercidas por pesquisadores de ponta nas diferentes disciplinas, a maioria em universidades, mas não apenas nelas. Eles estão envolvidos na produção de novo conhecimento a ser testado, criticado e avaliado por seus pares. É uma atividade altamente especializada e envolve linguagens e símbolos, como a matemática, que muitos de nós não entendem. Em algum ponto no meio do continuum, há um leque de tipos de conhecimento, inclusive o conhecimento especializado de muitas profissões e o conhecimento escolar ou currículo, que compõe os programas educacionais dos primeiros anos até os mestrados e doutorados. (YOUNG, 2014, p. 196).

A crise gerada na Universidade não é um facto novo. Boaventura Sousa Santos(1997, 2008,) tem escrito exaustivamente sobre os paradigmas que envolvem o seu papel e a sua importância, para além das crises geradas devido à sua perda de protagonismo. No Brasil, com a falta de investimento do Estado, as Universidades têm sentido o peso deste processo, bem como o que resulta da abertura de instituições no setor privado, iniciada na década de 1990. O número de instituições privadas ${ }^{17}$ intensificou-se, sobretudo através da oferta de cursos à distância (EaD), fazendo diminuir significativamente as matrículas no setor público, em alguns cursos. Ainda assim, o autor analisa a transnacionalização em curso em diferentes países, refletindo evidentemente sobre os mais periféricos, por isso vinculados às agendas colocadas pelo Banco Mundial e pela Organização Mundial do Comércio (Santos e Almeida, 2008). Tendo em conta que as Universidades Públicas são gratuitas, sendo a sua manutenção uma responsabilidade do Estado, o que tem estado em debate, como prerrogativa das políticas neoliberais, é a necessidade de diminuir os gastos públicos, fazendo com que as Universidades passem a ser um alvo fácil.

\footnotetext{
${ }^{17}$ A LDB em seu Art.o 52, definiu que somente são Universidades as instituições que possuem o tripé: ensino, pesquisa e extensão. De acordo com o Decreto $n$ o 5.773/06, as instituições superiores são; universidades, centros universitários e faculdades.
} 
Além do mais, na nossa pesquisa, os argumentos utilizados pelos entrevistados ligados ao MBNC, que contribuíram com insumos técnicos, pesquisas pelas empresas e institutos privados, são apontados por Santos e Almeida (2008) como sendo a ponta do iceberg, nos espaços ocupados, que a priori deveriam ser ocupados pelas Universidades e que ganham protagonismo na lacuna deixada,

(...)sob a égide da globalização neoliberal, organismos internacionais, organizações nãogovernamentais e uma plêiade de fundações e institutos privados têm vindo a assumir algumas das funções da universidade pública no desenvolvimento da educação pública, em especial no campo da pesquisa educacional aplicada. Esta mudança na titularidade das funções repercute-se no conteúdo do seu desempenho. Essa mudança manifesta-se na primazia das metodologias quantitativas, na ênfase em estudos de carácter avaliativo e de diagnóstico informados pela racionalidade económica, baseada na análise custo-benefício, e, finalmente, na preocupação obsessiva com a medição dos resultados da aprendizagem através da aplicação periódica de testes padronizados. Temas como eficiência, competição, performance, choice e accountability ganharam centralidade na agenda educacional. As pesquisas produzidas fora das universidades, patrocinadas e financiadas por organismos internacionais e fundações privadas, passaram a ter uma enorme influência sobre as políticas públicas de educação, condicionando as escolhas dos gestores dos sistemas públicos de ensino. (ibidem, p.74).

Neste momento, já é possível sinalizarmos que todos os entrevistados na nossa pesquisa, que redigiram o documento, independentemente das versões, demonstraram uma preocupação com a educação do país e, ao mesmo tempo, imbuídos pelo espírito da cidadania, procuraram contribuir com as suas experiências para enriquecer esse processo. Assim, deixaram clara a necessidade de garantir a todas as crianças e alunos o direito de aprender, dendo o mesmo fazer parte do ordenamento jurídico brasileiro.

\section{CONSIDERAÇÕES FINAIS}

Em jeito de conclusão, podemos afirmar que existiram disputas de toda ordem durante a elaboração da BNCC. Quer nos grupos políticos que lideraram o processo, quer nos grupos privados que procuraram disseminar os seus valores, quer, ainda, no âmbito das vaidades acadêmicas, que disputaram as suas experiências e a sua epistemologia, o processo foi, permanentemente, perpassado por conflitos e disputas. A construção de um currículo nacional não é um processo neutro, muito menos ingênuo, o que Apple (1982, p. 5) considera que "é produto das tensões, conflitos e concessões culturais, políticas e econômicas que organizam e desorganizam um povo".

O contexto de influência política na construção da BNCC envolveu uma ampla tecnologia na construção do documento. Atores, grupos corporativos, fundações privadas e familiares, as associações de Secretários de Educação e o Governo arquitetaram e tentaram fazer prevalecer as suas ideias, numa grande arena política em que lugares e grupos de interesse disputaram o seu protagonismo, bem como procuraram garantir a inclusão de sua agenda. 
A genealogia do discurso político, que envolve o processo de construção da BNCC, foi perseguido pela nossa pesquisa, para entender de que forma os distintos grupos contornaram obstáculos e dificuldades para fazerem valer as suas vozes, as suas conceções e, se não bastasse, os paradigmas utilizados na construção do documento. Ainda assim, a nova forma de governança passa a ser aludida pelo grupo empresarial representado pelo $\mathrm{MBNC}$, que patrocinou o documento, tendo ao mesmo tempo seguido as orientações do Banco Mundial, privilegiando as políticas de accountability. Na ordem do dia, o grupo tem tentado imprimir uma nova forma de gerenciamento da máquina estatal, procurando garantir o enredo das políticas neoliberais, onde o Estado não é mais fornecedor, mas passa a ser avalista (Ball, 2004) das grandes reformas educacionais.

A celeridade do processo chama à atenção, sobretudo na $\mathrm{V} 3$, a velocidade em que foi construída, gerando uma nova versão que, por sua vez, foi aprovada pelo CNE e homologada pelo MEC, em dezembro de $2017^{18}$. Assim sendo, não podemos apartar o processo político em que foi gerada, sempre em nome da urgência que o país tinha em resolver a complexidade, como se o currículo nacional, sozinho, pudesse equacionar os problemas decorrentes da baixa qualidade enfrentada na Educação Básica.

A opacidade que tem envolvido a sua génese requer a rejeição de enredos conhecidos pela sociedade e até pelos especialistas que empreenderam a sua construção. Na pesquisa realizada procurámos desvelar as posições controversas que envolvem todo o processo. No caso das primeiras versões (V1/2), a legitimidade dos atores selecionados, amplamente apresentados com um pendor democrático, seja pela sua escolha, seja pela transparência na fervura que a discussão deflagrou, como foi a consulta pública (na V1), que recebeu mais de 12 milhões de contribuições, seja nas audiências públicas (V2), com a realização de vinte e sete Seminários Estaduais, envolvendo 9275 participantes. Já na V3, a discussão contou com cinco (5) Audiências Públicas em cada região do país, com 283 manifestações orais.

Para a compreensão das forças políticas envolvidas e das relações de poder imbricadas, além das vozes, dos nós, do emaranhado de fios que encobre quer a sua génese, quer a epistemologia empregada em cada documento, foi feito o perscrutar de todo o processo percorrido.

A tentativa, por parte de alguns atores ligados ao MBNC e até de Agentes Públicos, de levantar suspeitas sobre o papel dos especialistas na redação do documento, sobretudo dos professores de IES,

\footnotetext{
${ }^{18}$ Somente a Educação Infantil e o Ensino Fundamental foram contemplados nessa primeira etapa, visto que o grupo que assumiu os trabalhos após o impeachement, retirou o Ensino Médio do documento, gerando a Lei no. 13.415/2017, por força da Medida Provisória no 746/2016. A BNCC do Ensino Médio foi aprovada em novembro de 2018 pelo CNE e homologada em dezembro pelo MEC.
} 
com carreiras consolidadas e envolvimento em pesquisas, compeliram-nos a compreender as fronteiras estabelecidas entre público e privado, e mesmo a recusa da sua contribuição para a educação no país. Com efeito, fazer assomar o papel desempenhado pela iniciativa privada nas “contribuições" colocadas em discussão, por meio de insumos técnicos e/ou pesquisas desenvolvidas para esse fim, tornou evidente a necessidade de redefinir o seu protagonismo e, ao mesmo tempo, de demarcar territórios.

A intenção do MBNC, em toda a sua trajetória na construção da BNCC, não foi a de discutir com os especialistas a Base, nomeadamente os conceitos e os objetivos de cada área, o que ficou claro nas narrativas dos entrevistados. Pelo contrário, os seus principais interesses foram de acompanhar todo o processo e de garantir a sua participação na implementação pelos Sistemas de Ensino, fato comprovado pelo número de Estados e Municípios que celebraram acordos com as entidades privadas ligadas ao movimento.

Não obstante, outro interesse que surge de forma clara é o da prestação de serviços educacionais, tanto na oferta de material didático e de conteúdos digitais, como da formação continuada de professores. A força do grupo conseguiu, neste momento, garantir acordos de cooperação técnica com o MEC, para disponibilizar recursos digitais às escolas e aos professores, hospedando os seus materiais no Portal do MEC (Diário Oficial da União, no 131, terça-feira, 10 de julho de 2018.), com principal visibilidade a Fundação Lemann e a Fundação Roberto Marinho, para além de outras entidades. No fundo, constrói-se a ideia da inoperacionalidade e incapacidade do setor público, de modo a criar condições para fazer florescer e consolidar o setor privado.

\section{REFERÊNCIAS}

ALMEIDA FILHO, N. A.; SANTOS, B. S. Universidade no século XXI: para uma universidade nova. Coimbra: Almedina; 2008.

APPLE, M. Ideologia e Currículo. São Paulo: Brasiliense, 1982. Editora, 1999.

. Políticas Culturais e Educação. Trad. João Menelau Paraskeva. Coleção Ciências da Educação. Porto, Porto

AVELAR, M.; BALL, S. J. Mapping new philanthropy and the heterarchical state: The Mobilization for the National Learning Standards in Brazil. In International Journal of Educational Development. Received 7 April 2017. Disponível em Journal Homepage: www.elsevier.com/locate/ijedudev (Acesso em 24/01/2018).

BALL, S. J. Performatividade, privatização e o Pós-estado do Bem-Estar social. In Educação e Sociedade. Campinas, vol. 25, n. 89, p. 1105-1126, Set./Dez. 2004. Disponível em http://www.cedes.unicamp.br (Acesso em 12/11/2017).

. Education reform: a critical and post structural approach. Buckingham: Open University Press, 1994

BERNSTEIN, Basil. Poder, educación y conciencia: sociología de la Transmisión Cultural. Santiago: Cide, 1988.

DALE, R. Globalização e educação: demonstrando a existência de uma "cultura educacional mundial comum" ou localizando uma "agenda globalmente estruturada para a educação"? In Educ. Soc., Campinas, vol. 25, n. 87, p. 423-460, maio/ago. 2004 423. Disponível em http://www.scielo.br/pdf/es/v25n87/21464.pdf (Acesso em 20/04/2016). 
FRIGOTO, G. Os circuitos da história e o balanço da educação no Brasil na primeira década do século XXI. In Revista Brasileira de Educação v. 16 n. 46 jan.|abr. 2011. Disponível em http://www.scielo.br/pdf/rbedu/v16n46/v16n46a13 (Acesso em 31/07/2018).

SANTOS, B. S. Pela mão de Alice. O social e o político na transição pós-moderna. São Paulo: Cortez, 1997.

2008.

; ALMEIDA Filho, N. A. Universidade no século XXI: para uma universidade nova. Coimbra: Almedina,

THIESEN, J. O avanço do conservadorismo nas políticas curriculares. In Revista Teias, v. 17 • v. 17 • n. 47 (Out-Dez, 2016). DOI: 10.12957/teias.2016.26615. Disponível em $\underline{\text { http://www.e- }}$ publicacoes.uerj.br/index.php/revistateias/article/viewFile/26615/19200 (Acesso em 30/04/207).

YOUNG, M. Teoria do currículo: o que é e por que é importante. In Cadernos de Pesquisa. Vol. 44, n. 151. São Paulo, jan/mar, 2014. ISSN 0100-1574. Tradução Leda Beck. Revisão técnica e notas: Paula Louzano. Disponível em http://www.scielo.br/pdf/cp/v44n151/10.pdf (Acesso em 28.03.2017). 


\section{O EMARANHADO DE FIOS QUE ENVOLVE OS CONTEXTOS DE INFLUÊNCIA E DE PRODUÇÃO DA BNCC}

Resumo: Analisar a trajetória do currículo nacional brasileiro levou-nos a campos extremamente controversos, que pela confirmação de alguns pressupostos, quer pela descoberta de pontos que tivemos que desocultar, ao percorrer alguns cenários e contextos desconhecidos, ou ignorados, mesmo pelos atores que nela estiveram envolvidos. Tivemos em conta as narrativas dos sujeitos implicados na sua construção, bem como dos consensos e dissensos inerentes a tal processo, e que nos falaram sobre a sua participação nas três versões do documento. Neste texto, partindo da análise da génese da Base Nacional Comum Curricular (BNCC), procuramos compreender a forma como foi concebida, quem iniciou o processo de construção, que grupos operaram e the deram suporte político, mesmo nos momentos da turbulência que o Brasil viveu, com a mudança de Governo, das equipes do MEC e do CNE, em 2016. Nesse contexto, por vezes contraditório, diferentes grupos reivindicam a mobilização, a construção e, finalmente, a sua implementação. Os fios e os nós que entretecem o contexto político da sua produção fazem parte da nossa pesquisa. Assim, para além da análise referida, este texto procura contribuir para o debate que se vem gerando em torno da BNCC, incidindo no processo de (re)construção do currículo nacional, em particular nos sentidos e decisões subjacentes ao contexto da sua produção. Os resultados preliminares de uma investigação que vimos desenvolvendo, há algum tempo, permitiram dar eco as vozes que deram sentido ao texto aprovado.

Palavras-chave: Currículo; BNCC; génese e protagonismo.

\section{THE TANGLE OF THREADS SURROUNDING THE CONTEXTS OF INFLUENCE AND PRODUCTION OF THE BRAZILIAN NATIONAL CURRICULAR BASE}

Abstract: Analyzing the trajectory of the Brazilian national curriculum led us to extremely controversial fields, either through the confirmation of some assumptions or through the discovery of points thatwehad to uncover, by going through unknown and ignored scenarios or contexts, evenby the actors who were involved in it.we have taken into account the narratives of the subjects involved in its construction, as well as the consensus and dissentinherent in that process, whichtold us about their participation in the three versions of the document. In this text, based on the genesis analysis of the National Curricular Base (BNCC), we tried to understand how it was conceived, who started the construction process, which groups operated and gave it political support, even in these times of turbulence that Brazil has been going through, with the change of Government, and of the MEC (Ministry of Education and Culture) and CNE (National Education Council) teams, in 2016. In this context, sometimes contradictory, different groups demand the mobilization, the construction and, finally, its implementation.The wires and knots that entertain the political context of its production are part of our research. Thus, in addition to the afore mentioned analysis, this texts eeks to contribute to the debate that is being generated around the BNCC, focusing on the process of (re) construction of the national curriculum, in particular in the senses and decisions underlying the context of its production. The preliminar $y$ results of na investigation that we have been developing for some time havemade it possible to echo the voices that have meaning to the text approved.

Keywords: Curriculum; BNCC; Genesis and protagonism.

Submetido em Julho de 2019

Aprovado em Novembro de 2019

Revista Teias v. $20 \bullet$ n. 59 • out/dez 2019 • Outras epistemologias e metodologias nas investigações sobre currículo 250 